\title{
Effects of blast ring burden and explosive density on fragmentation and ore recovery in sublevel cave mines
}

\author{
AD Campbell Beck Engineering, Australia
}

\begin{abstract}
Numerous studies have proved that blast design impacts gravity flow in sublevel cave mines. However, such designs are yet to be fully optimised owing to the small number of mines with published full-scale experimental studies specifically planned to measure the effect of blast design variables on fragmentation and recovery. This paper details the results of a three-year experimental program undertaken at the Ernest Henry sublevel cave mine. The program consisted of 162 production blast rings conducted over six experimental trials to quantify the impact of ring burden, explosive density and crosscut height on gravity flow and recovery. The results of the research program are split between this paper and another entitled 'Full-scale experiments to measure the effect of crosscut height on recovery in sublevel cave mines' (Campbell 2018).

The impact of ring burden and explosive density on fragmentation and recovery was quantified using full-scale experiments. Electronic cave markers were used to measure recovery over multiple sublevels and the extraction zone evolution in real time. Fragmentation was measured during loading since the size of the fragmented rock is known to affect gravity flow behaviour and ore recovery in sublevel cave mines. The size distribution of the fragmented rock from blasting was measured using high-resolution 3D laser scanning technology.

Results of the experimental programs prove that ring burden and explosive density have a significant impact on ore recovery. Cumulative secondary recovery was between 8 and $10 \%$ higher on average for the reduced explosive density and increased ring burden trials compared with the baseline measurements. The effect of blast design variables on fragmentation was found to be less than expected. The experimental outcomes differ from earlier theories and the research hypotheses, which predicted the opposite effect on recovery for changes in ring burden and explosive density. Underground observations and detailed analysis are used to explain the results.

Although the results are affected by the mine design and rock mass conditions at the mine and therefore site-specific, the findings on the relative impact of design variables on fragmentation and recovery are potentially transferable to other sublevel cave (SLC) mines. Additional site-specific testing is required to confirm the impact of design variables in different conditions and is recommended prior to selecting or altering blast design parameters.
\end{abstract}

Keywords: blast design, fragmentation, gravity flow, recovery, sublevel caving

\section{Introduction}

Sublevel caving (SLC) is a high-production, low-cost underground mass mining method suitable for extracting mineral resources safely at depth. However, the method has the disadvantages of greater dilution and ore loss compared with some other mining methods. Blasting, fragmentation and gravity flow are known to influence dilution and recovery, but currently the interrelationship between these factors is neither fully understood nor quantified. Furthermore, the effects of some blast design parameters on fragmentation and recovery are yet to be quantified using full-scale experiments and modern measurement devices. These gaps in knowledge prevent optimisation of mine layout and blast design in SLC mines to maximise financial return.

In this research, a full-scale experimental program in an operating SLC mine was conducted to further understand gravity flow and recovery for different blast design parameters. The purpose was to measure the effect of blast design variables on detonation performance, rock fragmentation, gravity flow mechanics and 
recovery in controlled, production-scale experiments. The aim of this research is to improve recovery in SLC mines by testing the effect of blast design parameters hypothesised to increase recovery in previous studies. These parameters were explosive density, blast ring spacing and crosscut height. This paper details the results of the experiments related to ring burden and explosive density. An accompanying paper in the conference proceedings details the results of the crosscut height trials (Campbell 2018).

Small-scale experiments have been conducted to simulate gravity flow in SLC mines and to measure the effect of different variables on gravity flow (Free 1970; Janelid \& Kvapil 1966; McCormick 1968; Panczakiewicz 1977; Peters 1984; Stazhevskii 1996). These experiments provide valuable insight into gravity flow behaviour, including the effects of particle size, overburden confinement, blast ring angle and crosscut dimensions. However, these models have similitude issues and previous researchers found it difficult to simulate the impact of blasting and then measure the impact on material flow and recovery.

Full-scale experiments have been conducted in operational SLC mines to measure gravity flow behaviour and the impact of mine design variables on ore recovery (Gustafsson 1998; Hollins \& Tucker 2004; Kosowan 1999; Power 2004; Quinteiro et al. 2001). These experiments, particularly in larger mining geometry in modern SLC mines, identified that gravity flow is less uniform than measured in scale models and early full-scale experiments (Gustafsson 1998; Hollins \& Tucker 2004; Power 2004). Blasting is known to affect gravity flow owing to material compaction, swell and movement during blasting (Brunton 2009; Bull \& Page 2000; Cullum 1974; Gustafasson 1998; Johansson 2011; Just et al. 1973; Power 2004; DeGagne \& McKinnon 2006; Rustan 2000). Full-scale experiments revealed that gravity flow, including recovery and dilution, are affected by blasting and the resulting size distribution of the fragmented rock (Brunton 2009; Wimmer 2010). However, few specifically planned full-scale experiments to quantify the effects of blast design on fragmentation and gravity flow are published.

\section{Experimental program}

A total of 162 production blast rings in six separate trials were conducted as part of the experimental program. The full-scale trials were conducted at the Ernest Henry mine (EHM) in northwest Queensland. Details of the mine and drill and blast parameters are provided in the accompanying paper (Campbell 2018).

The experimental program for this research was developed following an extensive literature review to understand current limitations in knowledge as well as recommendations made by Power (2004) and Brunton (2009) to improve the recovery in SLC mines. The specific aims of the full-scale experimental program were to:

1. Determine the effect of explosive density on SLC recovery.

2. Determine the effect of ring burden on SLC recovery.

3. Determine the effect of crosscut height on SLC recovery.

4. Quantify and compare fragmentation resulting from different explosive energy distributions in semi-confined blasting conditions.

5. Compare detonation performance of different blast designs.

6. Further understand gravity flow mechanisms by using electronic markers to measure SLC recovery in real time.

7. Determine design parameters to improve ore recovery and/or reduce mining costs in SLC mines.

8. Find interrelationships between blasting, fragmentation and gravity flow.

This paper details experimental outcomes for aims 1, 2, 4 and 7. To meet the aims of this research, the following full-scale experimental programs were completed:

- Trial Program 1: current EHM blast design (2.6 m ring burden, $1.1 \mathrm{~g} / \mathrm{cc}$ emulsion density).

- Trial Program 2: reduced crosscut height from 5 to $4 \mathrm{~m}$. Please refer to the accompanying paper for details of this experimental program (Campbell 2018). 
- Trial Program 3: reduced explosive density from 1.1 to $0.9 \mathrm{~g} / \mathrm{cc}$.

- Trial Program 4: increased explosive density from 1.1 to $1.25 \mathrm{~g} / \mathrm{cc}$.

- Trial Program 5a: initial testing of $2.2 \mathrm{~m}$ ring burden to determine if overbreak would prevent blasthole collars from being accessed.

- Trial Program 5: reduced ring burden by $15 \%$, from 2.6 to $2.2 \mathrm{~m}$.

- Trial Program 6a: initial testing of $3 \mathrm{~m}$ ring burden to determine if a larger burden could be broken successfully without the blast 'freezing', resulting in significant amounts of oversize.

- Trial Program 6: increased ring burden by $15 \%$, from 2.6 to $3 \mathrm{~m}$.

Each trial program consisted of 10 blast rings on the primary recovery level in which a blast variable was altered and the impact on detonation performance, fragmentation and recovery measured. Each trial program was conducted over five rings in two neighbouring crosscuts, and smart markers (Elexon Mining 2017) were installed in the middle three blast rings for a total of six blast rings monitored using smart markers per trial. Blast variables in each trial program were also varied on the secondary recovery level in the three crosscuts below to measure the impact of blast variables on secondary recovery. The alternate blast design was applied to five blast rings in each of the three crosscuts below the primary recovery level as shown in Figure 1. Each blast variable tested within each trial program was applied to 25 blast rings on the primary and secondary recovery levels. The smart marker detection system and marker layout are detailed in the accompanying paper (Campbell 2018).

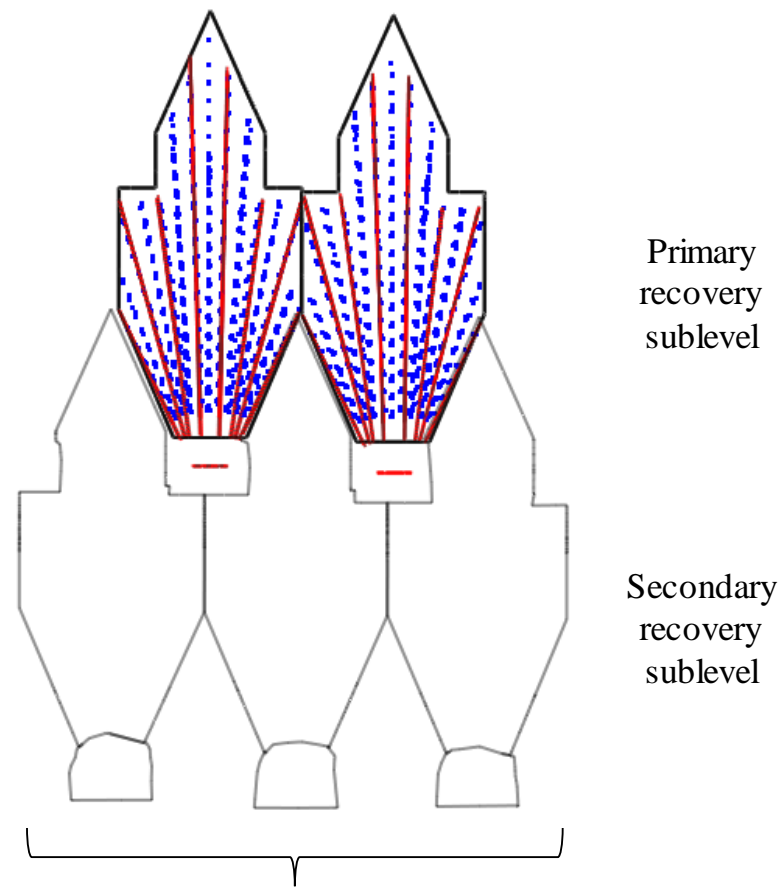

Blast variable applied for five blast rings per cross cut on the secondary recovery sublevel

Figure 1 Application of blast variables for primary and secondary recovery levels (front view) 
The objective of Trial Program 1 was to measure detonation performance, fragmentation and recovery under normal blasting conditions to develop a reference dataset. This experiment used the standard EHM blast design (as described by Campbell 2018), more specifically, an eight-hole pattern with $2.6 \mathrm{~m}$ ring burden, $102 \mathrm{~mm}$ blastholes and emulsion density of $1.1 \mathrm{~g} / \mathrm{cc}$. Altering the crosscut height (Trial Program 2) was proven not to have a statistically significant impact on recovery (Campbell 2018). Since the blast design was not altered, it was decided that the recovery results for both Trial Programs 1 and 2 would be combined to form a larger baseline dataset.

The purpose of Trial Programs 3 and 4 was to quantify the effect of explosive density on detonation performance, fragmentation and recovery. Drawpoint observations and marker recovery patterns were used to interpret the effect on gravity flow mechanisms. The explosive density was decreased to $0.9 \mathrm{~g} / \mathrm{cc}$ and increased to $1.25 \mathrm{~g} / \mathrm{cc}$. This was the lowest and highest density achievable without changing the explosive type used at EHM. The change in density to 0.9 and $1.25 \mathrm{~g} / \mathrm{cc}$ in $102 \mathrm{~mm}$ blastholes resulted in approximately the same energy distribution as that of 89 and $115 \mathrm{~mm}$ blastholes, respectively, with an emulsion density of $1.1 \mathrm{~g} / \mathrm{cc}$. Therefore, Trial Programs 3 and 4 could be used as a proxy for the effect of an alternate blasthole diameter.

Altering the explosive density, and thus altering the powder factor and energy distribution, is a means to alter the fragmentation size, the amount of backbreak and potentially the detonation performance. These factors were hypothesised to influence gravity flow mechanics and recovery. Increasing explosive density is a method to increase the powder factor without additional blastholes or larger diameter holes. Decreasing the density is a means of potentially reducing backbreak, reducing explosive costs and not 'over-blasting' the rock. It was hypothesised that recovery could be increased by increasing the explosive density. More specifically, increasing the explosive density was predicted to result in smaller fragmentation, which then translates to more regular mass flow, thus resulting in higher recovery.

Trial Programs 5 and 6 used a smaller and larger ring burden of 2.2 and $3 \mathrm{~m}$ respectively. Altering the ring burden has the effect of changing the volume of material to be blasted, which affects the explosive energy distribution and powder factor. Altering the ring burden also affects the depth of draw relative to the depth of the ring and directly affects mining costs for drilling and blasting. Power (2004) hypothesised that the increase in recovery achieved by reducing the ring burden would offset any increase in mining costs. Conversely, Dunstan and Power (2010) recommended conducting a full-scale experimental program to determine if blast ring burdens larger than $2.5 \mathrm{~m}$ could be effectively broken using $102 \mathrm{~mm}$ diameter blastholes and to measure the effect on recovery.

The smaller ring burden of $2.2 \mathrm{~m}$ was selected since backbreak at the brow was commonly measured between 1.5 and $2 \mathrm{~m}$ at EHM. Brow damage and backbreak larger than the ring burden would prevent access to blasthole collars to connect detonating cords and prevent a ring from being blasted, which is highly undesirable.

Recovery in ring burdens larger than $2.6 \mathrm{~m}$ (using $102 \mathrm{~mm}$ diameter blastholes) have not been extensively tested in SLC mines with comparable ground conditions and mine layouts. As a result, the increase in ring burden for the trial was limited to $3 \mathrm{~m}$. The increase and decrease in the ring burden trials from the standard $2.6 \mathrm{~m}$ ring burden was $0.4 \mathrm{~m}$, or $15 \%$. The Kiruna and Malmberget SLCs in Sweden use a $3 \mathrm{~m}$ ring burden in combination with $115 \mathrm{~mm}$ blastholes. Although the blast ring shape in the Swedish iron ore mines differs from those used in Australia, the larger ring burden is justified using the larger blasthole diameter. The combination of $3 \mathrm{~m}$ ring burden and $115 \mathrm{~mm}$ blastholes has a burden to blasthole diameter ratio of 1:26, which is close to the guideline of 1:25 when using emulsion explosives (Hustrulid 2000). 
To measure the impact of ring burden on recovery, it was also decided to alter the ring burden to the extent practical. However, limited benchmarking was available to decide these limits. For these reasons, preliminary testing was completed for the 2.2 and $3 \mathrm{~m}$ burden trials to determine if the alternate ring burdens could be successfully blasted. Prior to testing, the operational team at EHM was unsure if the reduced ring burden would cause excess backbreak and result in hole loss in the proceeding ring, or if the larger burden would cause the blasted material to 'freeze' or result in excessive oversize material.

A frozen ring is when rock is blasted but is not sufficiently broken to result in material flow. The financial risk to the mine owing to a lost blast ring and operational delays was significant should it occur in the main SLC where the marker trials were planned. For this reason, a low-risk area of the mine was selected for the initial testing of the 2.2 and $3 \mathrm{~m}$ ring burdens. These initial trials are denoted as Trial Program 5a and 6a for the 2.2 and $3 \mathrm{~m}$ ring burdens respectively. The trials were successful and were used to convince mine management that an alternate ring spacing could be successfully blasted. Thus, approval for marker Trial Programs 5 and 6 was obtained. The alternate ring burden was also maintained for the test rings below the marker trials on the secondary recovery levels to ensure the effects of each ring burden was measured for each stage of recovery.

Drawpoint fragmentation was measured using laser scanning and automated particle delineation algorithms as detailed by Campbell and Thurley (2017). Photography and post-blast inspections of the drawpoint condition and brow damage were also conducted when laser scanning was undertaken. This approach enabled fragmentation measurements to be correlated with assessments of brow wear and observations such as preferential draw, hang-ups, blockage of flow, fines entry and oversize, to be recorded. Inspection forms were filled out during each underground inspection and information compiled in a database.

\section{$3 \quad$ Results}

\subsection{Fragmentation}

A total of 367 laser scans were conducted to measure the size of rock fragments at the drawpoint after blasting and during loading of the blast design trials. Scans were conducted during loading at 250 to $500 \mathrm{t}$ increments on the primary recovery level only. Fragmentation results are provided in Table 1 and Figure 2.

Fragmentation measurements identified the following phenomena:

- A negative relationship exists between explosive density and all fragmentation metrics except fines (material less than $50 \mathrm{~mm}$ in diameter). As the explosive energy was reduced by decreasing the explosive density, the $P_{50}$ and $P_{80}$ fragmentation sizes increased. The opposite effect was measured when the explosive density was increased, as expected. The explosive density had no obvious effect on the amount of fines, which indicates that more fines are generated as secondary fragmentation or recovered from levels above than in the crushed zone around the blastholes.

- $\mathrm{P}_{50}$ and $\mathrm{P}_{80}$ have a moderate negative relationship with ring burden. That is, as ring burden increases, the $P_{50}$ and $P_{80}$ metrics decrease. This was unexpected since reducing the ring burden causes the powder factor to increase. A higher powder factor would normally result in the $P_{50}$ and $\mathrm{P}_{80}$ size being decreased. A plausible explanation for the measured result is that reducing the ring burden results in higher blast confinement, which has been demonstrated to result in reduced fragmentation and larger particle sizes in laboratory blasting experiments (Johansson 2011) and in underground trials (Wimmer et al. 2013). For this reason, increasing explosive energy distribution by reducing the ring burden does not necessarily result in smaller fragmentation.

- The amount of fines material was highest in Trial Program 6, which may be related to the higher frequency of low hang-ups caused by large blocks being caught at the brow. The fines material was regularly observed as flowing around these large blocks and possibly originated from levels above. 
Table 1 Summary of fragmentation parameters for combined measurements for each trial

\begin{tabular}{|c|c|c|c|c|c|c|}
\hline Trial number/test variable & $\begin{array}{l}\text { Number } \\
\text { of scans }\end{array}$ & $\begin{array}{l}\text { Number of } \\
\text { measured } \\
\text { particles }\end{array}$ & $\begin{array}{l}\text { Mean } \\
\text { particle } \\
\text { size }(\mathrm{mm})\end{array}$ & $\begin{array}{l}P_{20} \\
(\mathrm{~mm})\end{array}$ & $\begin{array}{l}P_{50} \\
(\mathrm{~mm})\end{array}$ & $\begin{array}{l}P_{80} \\
(\mathrm{~mm})\end{array}$ \\
\hline Trial Program 1 (baseline) & 127 & 88,816 & 122 & 96 & 215 & 398 \\
\hline $\begin{array}{l}\text { Trial Program } 3(0.9 \mathrm{~g} / \mathrm{cc} \\
\text { explosive density) }\end{array}$ & 47 & 30,797 & 130 & 107 & 229 & 431 \\
\hline $\begin{array}{l}\text { Trial Program } 4 \text { ( } 1.25 \mathrm{~g} / \mathrm{cc} \\
\text { explosive density) }\end{array}$ & 41 & 28,255 & 122 & 89 & 204 & 372 \\
\hline Trial Program 5 (2.2 m burden) & 38 & 22,909 & 131 & 95 & 224 & 417 \\
\hline Trial Program 6 ( 3 m burden) & 52 & 31,870 & 129 & 54 & 207 & 390 \\
\hline $\begin{array}{l}\text { Trial Program 5a (initial } 2.2 \mathrm{~m} \\
\text { burden testing) }\end{array}$ & 28 & 18,629 & 120 & 107 & 209 & 356 \\
\hline $\begin{array}{l}\text { Trial Program 6a (initial } 3 \mathrm{~m} \\
\text { burden testing) }\end{array}$ & 34 & 20,271 & 129 & 113 & 224 & 399 \\
\hline
\end{tabular}

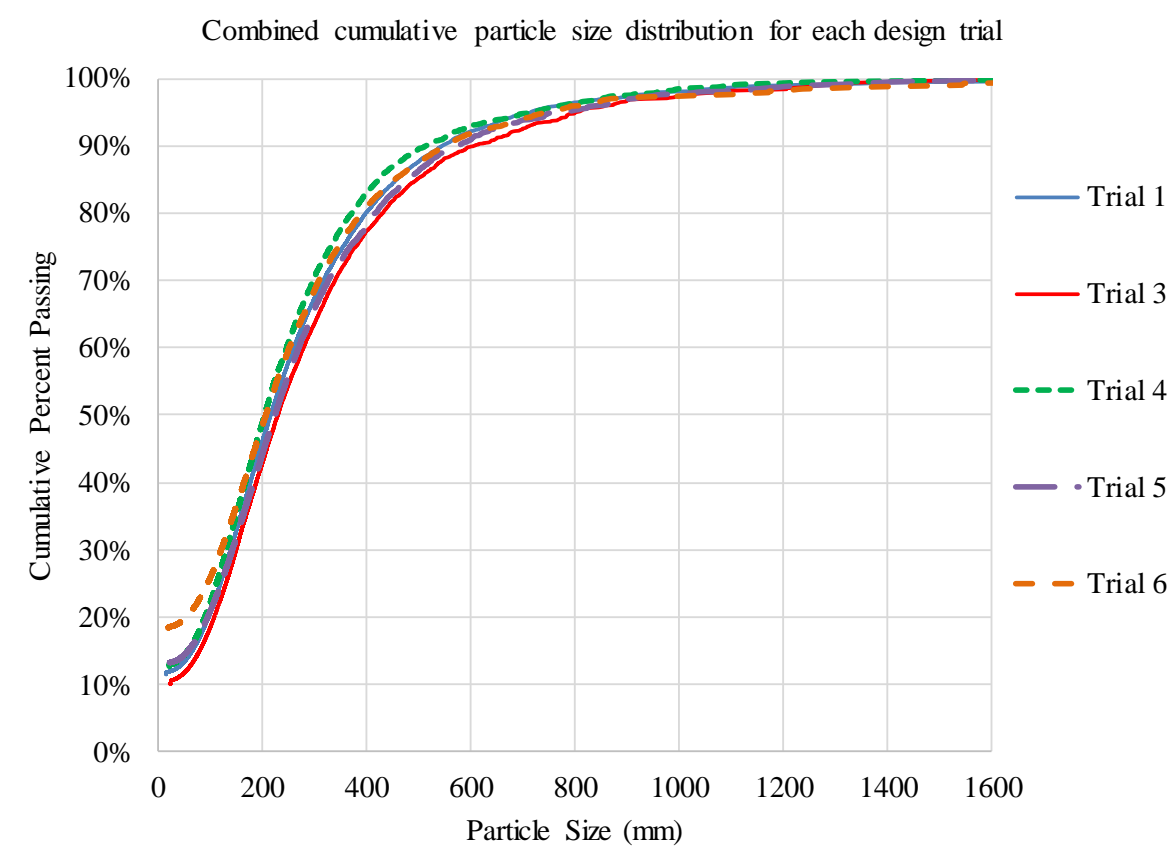

Figure 2 Combined particle size distributions for fragmentation measurements in each trial program

Oversize blocks (boulders larger than $1.2 \mathrm{~m}$ ) were recorded during drawpoint inspections and fragmentation measurements. No statistically significant differences in oversize between trials were confirmed using this data. However, these were point measurements in time and do not record all oversize events. Operator shift reports and the production database were reviewed to understand the amount of oversize occurring during each trial program. The amount of oversize by tonnage reported for blast rings in each trial program for both the primary and secondary recovery levels is provided in Table 2 . The oversize tonnage as a percentage of the total draw tonnage is also provided. The results demonstrate that altering the blast design parameters had little effect on the amount of oversize (by percentage of ring tonnes). Much of the recorded oversize at $\mathrm{EHM}$ is late in the ring draw and of the same geology as the hanging wall, indicating that much of the recovered oversize is in fact outside the orebody, which is not blasted. 
Table 2 Oversize reported during loading in each trial program (primary and secondary rings)

\begin{tabular}{lll}
\hline Trial number/test parameter & $\begin{array}{l}\text { Average oversize } \\
\text { tonnage per blast ring }\end{array}$ & $\begin{array}{l}\text { Percent oversize } \\
\text { by tonnes }\end{array}$ \\
\hline Trial Program 1 (baseline) & 84.3 & 1.7 \\
Trial Program 2 (reduced crosscut height) & 111.6 & 2.4 \\
Trial Program 3 (0.9 g/cc explosive density) & 86.5 & 1.8 \\
Trial Program 4 (1.25 g/cc explosive density) & 98.3 & 2 \\
Trial Program 5 (2.2 m ring burden) & 57.8 & 1.4 \\
Trial Program 6 (3 m ring burden) & 106.2 & 1.9 \\
\hline
\end{tabular}

\subsection{Recovery}

Ring recovery was determined using Leapfrog ${ }^{\circledR}$ software (ARANZ Geo Limited 2018) to interpolate recovery volumes. The method for interpreting the recovery volume is detailed further in Campbell (2018). It should be noted that one marker ring in Trial Program 5 was excluded from the analysis after being identified as an extreme outlier. Analysis for Trial Programs 1 and 2 provided no evidence for a difference in group means and Campbell (2018) concluded that altering the crosscut height had no statistically significant impact on primary recovery (including backbreak). As the results of Trial Programs 1 and 2 are not statistically different, the results of both trials have been amalgamated into a single baseline dataset for the remainder of the analysis. Results of the blast design experiments are provided in Table 3. The results are summarised below:

- The mean primary recovery (including backbreak) measured for the standard blast design in Trial Program 1 was $54.7 \%$ and cumulative secondary recovery was measured to be $71.3 \%$.

- The combined baseline (Trial Programs 1 and 2) had an average cumulative primary and secondary recovery of 53.2 and $68.9 \%$ respectively.

- The trials with the highest recovery were Trial Programs 3 and 6. Trial Program 3 measured 61.1\% primary recovery (including backbreak) and 78.8\% cumulative secondary recovery. Trial Program 6 measured $63.8 \%$ primary recovery (including backbreak) and $77.2 \%$ cumulative secondary recovery. Both trials correspond to blast design changes that reduced the available blast energy, or powder factor, of the blast. This suggests that reducing the amount of blast energy increases recovery, possibly by reducing compaction of the blasted and cave material.

- Primary recovery (including backbreak) in Trial Programs 3 and 6 was 7.9 and $10.6 \%$ higher, respectively, compared with the baseline recovery. Cumulative secondary recovery in Trial Programs 3 and 6 was 9.9 and $8.3 \%$ higher on average compared with the combined baseline dataset.

- Increasing the explosive density (Trial Program 4) was found to cause significant variability in recovery. This may also be linked to the previous point, where high blast energy is linked to over-compaction of cave material and reduced recovery. Trial Program 4 resulted in the lowest recovery of all the trials with an average primary recovery (including backbreak) of $31.9 \%$ and average cumulative secondary recovery of $47.8 \%$. This is approximately $21 \%$ lower on average than the baseline for both primary and secondary recovery.

- Reducing the ring burden in Trial Program 5 was measured to have an average primary recovery (including backbreak) of $52.4 \%$ and average cumulative secondary recovery of $62.7 \%$, which is lower than the combined baseline recovery measurements.

- The statistical power of the experiments was found to be 0.86 and 0.93 for the explosive density and ring burden trials, respectively, for cumulative secondary recovery. Statistical power is the probability that a study will identify an underlying effect given that there is one there to detect. 
This is not the same as statistical significance, which gives the probability that the observed result occurred due to chance and not an underlying effect. A target statistical power of 0.8 is generally used in field experiments and exceeding this criterion means there was a sufficient number of tests in each trial program.

Table 3 Mean recovery results for each trial program

\begin{tabular}{llll}
\hline Trial number/test parameter & $\begin{array}{l}\text { Number of } \\
\text { blast rings } \\
\text { with smart } \\
\text { markers }\end{array}$ & $\begin{array}{l}\text { Average primary } \\
\text { recovery (including } \\
\text { backbreak) } \\
\text { (std dev.) }\end{array}$ & $\begin{array}{l}\text { Average cumulative } \\
\text { secondary recovery } \\
\text { (std dev.) }\end{array}$ \\
\hline $\begin{array}{l}\text { Trial Program } 1 \text { (baseline) } \\
\text { Trial Program } 2 \text { (reduced crosscut height) }\end{array}$ & 6 & $\begin{array}{l}54.7 \%(7.5) \\
51.6 \%(6.9)\end{array}$ & $\begin{array}{l}71.3 \%(4.9) \\
66.6 \%(6.7)\end{array}$ \\
$\begin{array}{l}\text { Trial Program } 3 \text { (0.9 g/cc explosive } \\
\text { density) }\end{array}$ & 6 & $61.1 \%(6.1)$ & $78.8 \%(6.3)$ \\
$\begin{array}{l}\text { Trial Program } 4 \text { (1.25 g/cc explosive } \\
\text { density) }\end{array}$ & 6 & $31.9 \%(20.9)$ & $47.8 \%(24.0)$ \\
$\begin{array}{l}\text { Trial Program } 5 \text { (2.2 m ring burden) } \\
\text { Trial Program } 6 \text { (3 m ring burden) }\end{array}$ & 5 & $52.4 \%(4.7)$ & $62.7 \%(4.6)$ \\
$\begin{array}{l}\text { Trial Programs } 1 \text { and } 2 \text { (combined } \\
\text { baseline) }\end{array}$ & 12 & $63.8 \%(7.7)$ & $77.2 \%(6.5)$ \\
\hline
\end{tabular}

It was hypothesised that recovery would be increased when the explosive energy distribution was increased. This is owing to the higher explosive energy causing more breakage and reducing the fragmentation size of the blasted rock, which promotes mass flow conditions. The results of the trial programs shown in Figure 3 demonstrate that this hypothesis was not correct. In fact, increasing the explosive density reduced recovery.

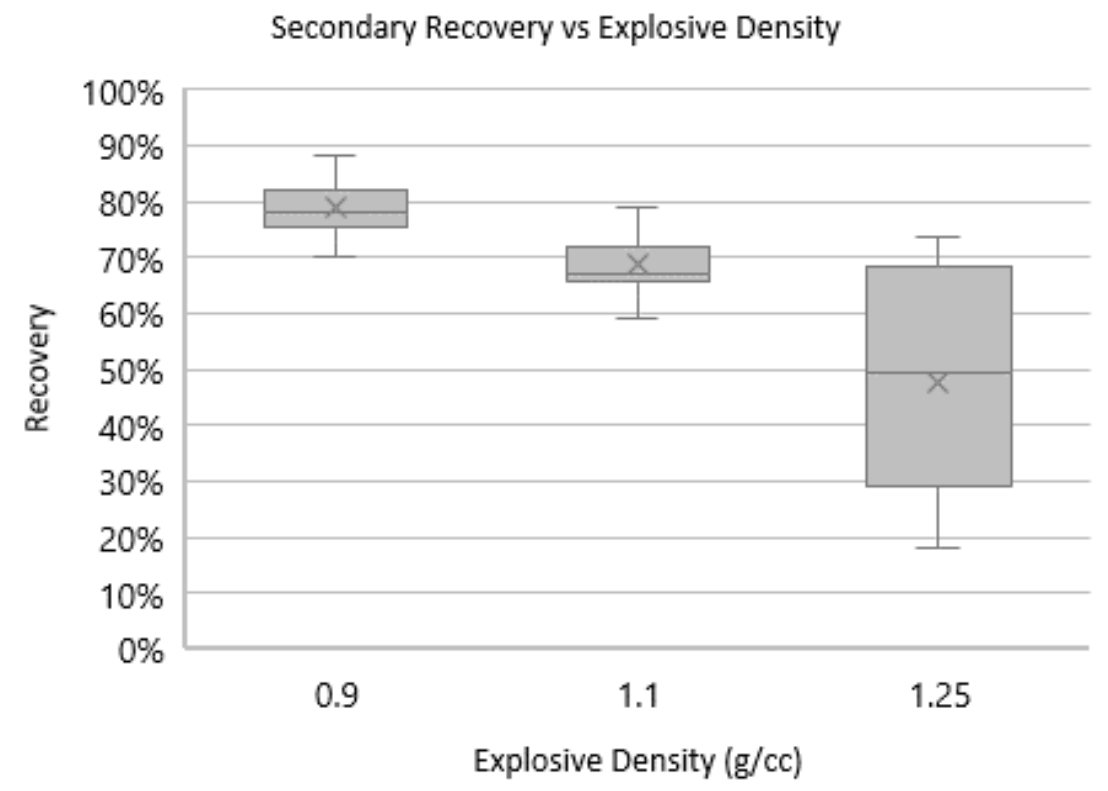

Figure 3 Plot of measured recovery as a function of explosive density

An explanation for the results is that reducing the amount of blast energy reduces the amount of compaction caused in the blasted and caved material. Reduced compaction minimised hang-ups and dilution entry from sublevels above. Over-compaction and poor flow conditions were observed to be more common when the explosive energy was increased. Three blast rings suffered significant hang-ups caused by the over-compaction 
of the blasted ore in Trial Program 4. The compaction was enough to cause the blasted ore (with visible smart markers) to form a vertical wall, enabling diluting material to collapse from levels above into the slot and report to the drawpoint once the hang-up was removed. An example of such a formation is provided in Figure 4.

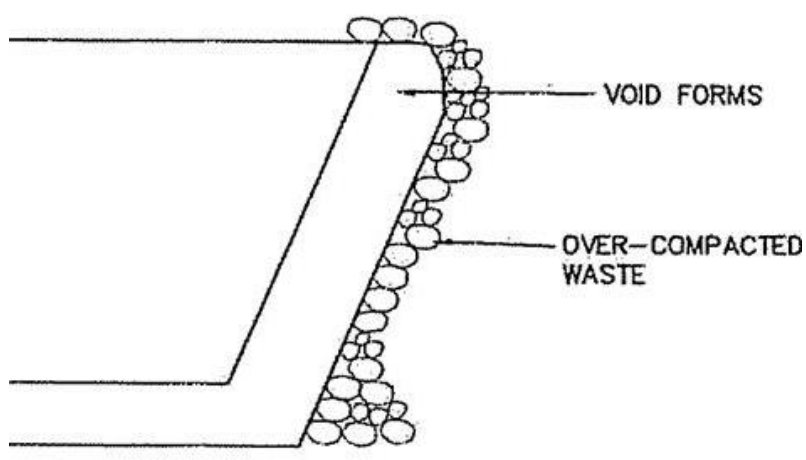

(a)

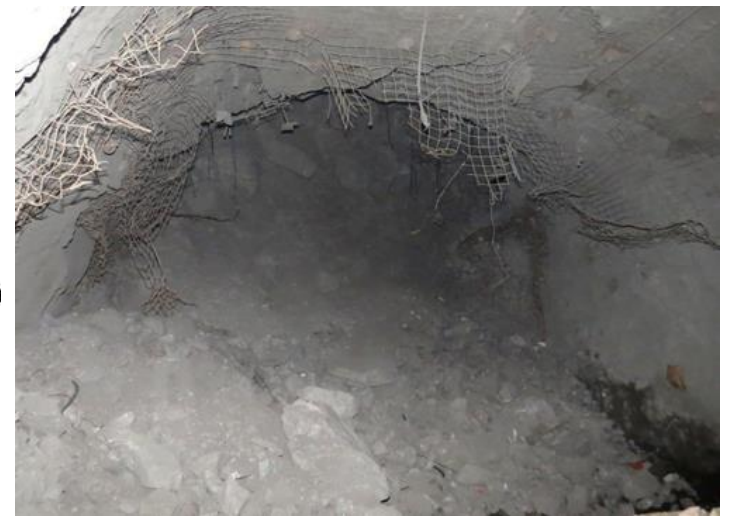

(b)

Figure 4 (a) A schematic of a wall formation (after Page \& Bull 2001); and, (b) An example of an open drawpoint with a wall of over-compacted ore

It was hypothesised in this study that recovery is inversely proportional to ring burden - or more specifically, as ring burden is reduced, recovery increases. This is because the measured depth of draw in previous marker recovery studies found a relatively high frequency of shallow draw, with low recovery occurring in the back of the ring. Marker recovery results demonstrate that the hypothesis was incorrect. Figure 5 shows the relationship between ring burden and recovery demonstrating that recovery increased as the burden was increased (for the ring burdens tested). This behaviour is explained by material flow observations such as in the explosive density trial programs where the decrease in ring burden (and increase in powder factor) corresponded to over-compaction of previously blasted and cave material resulting in unfavourable gravity flow behaviour. However, the reduction in ring burden did not result in the poor recovery measured when the explosive density was increased in Trial Program 4. It is still believed that reducing ring burden may increase recovery in some mining conditions owing to the change in ring geometry. However, the results demonstrate the negative impact of over-compaction was more than the recovery improvement owing to the change in geometry when the ring burden was reduced.

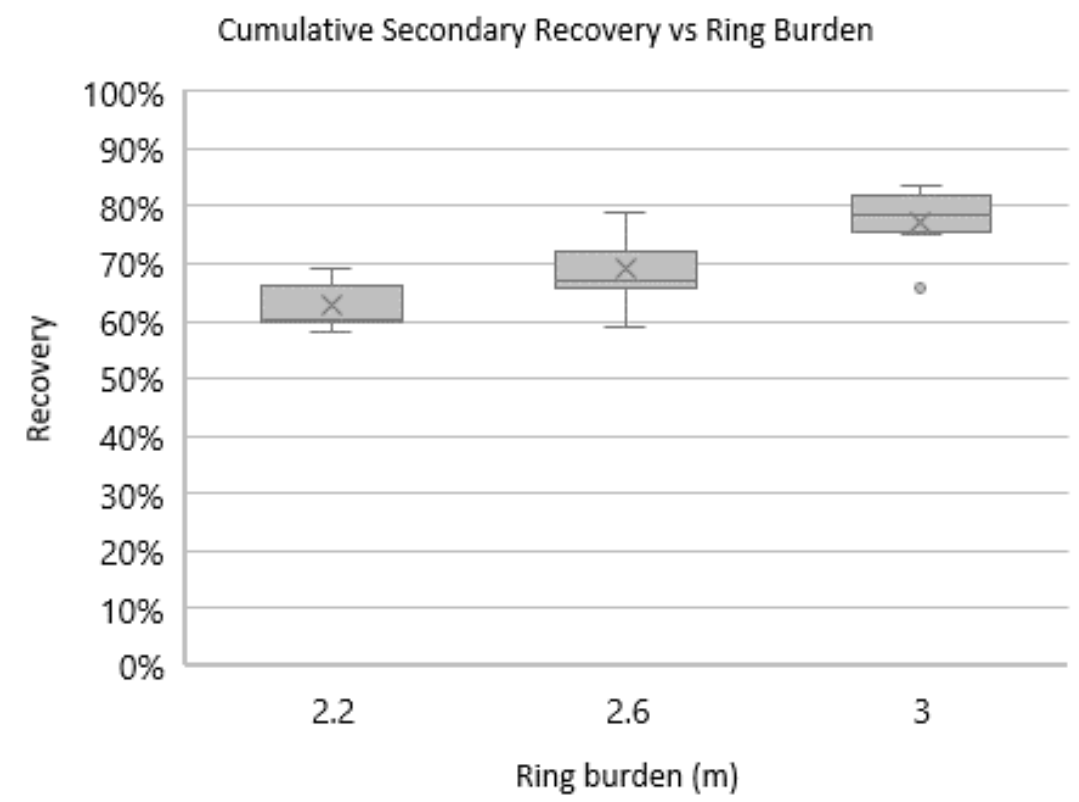

Figure 5 Plot of measured recovery as a function of ring burden 
The powder factor for a blast is the ratio of explosive weight to the tonnage of rock to be broken in the blast ring. Altering the explosive density and blast ring burden resulted in the explosive charge weight and ring tonnage to differ from the standard blast design at EHM. As a result, each of the experimental blasts within each trial program had a unique powder factor. Powder factor can also be used as a parameter to directly compare the explosive density and ring burden experiment results. A comparison between powder factor and recovery found a trend of increased recovery for blasts with a lower powder factor (Figure 6). The goodness of fit of the linear regression trend line is quite low $\left(r^{2}=0.2801\right)$. However, the trend line does indicate a correlation between powder factor and recovery. This result confirms that in the rock mass conditions at EHM, decreasing the powder factor had a positive impact on recovery. However, it is hypothesised that further reduction of the powder factor is likely to result in blast rings 'freezing' and poor ring breakage. It is suspected that an optimum powder factor exists for each rock mass in semi-confined blasting conditions, similar to a cutoff grade 'hill of value' scenario. Additional testing is required to determine the optimum for EHM as well as other mines. It is highly likely that the optimum will vary under different rock mass and mining conditions, especially when in situ grade and mining costs are included in the decision-making process.

Powder factor versus all recovery

(Backbreak, primary and secondary)

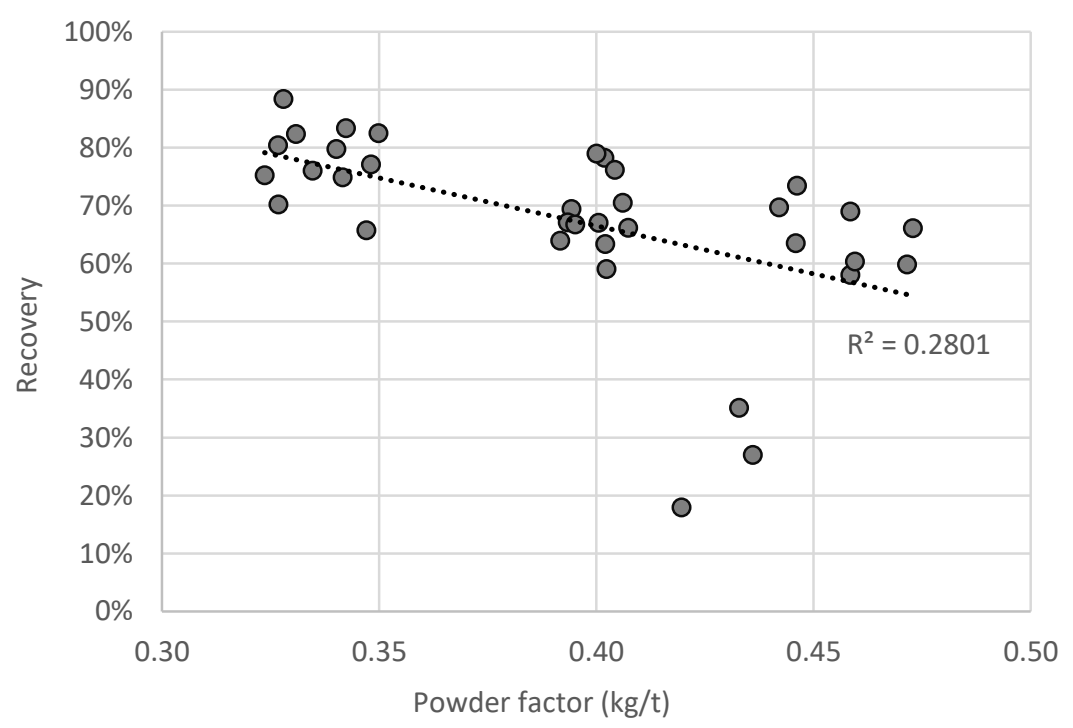

Figure 6 Recovery as a function of powder factor

\section{Discussion}

Blasting in SLC mines in the past has generally been focused on breaking rock rather than maximising recovery. In fact, blast design guidelines in SLC mines are largely based on rules of thumb and benchmarking, and are not optimised to site-specific conditions to maximise mine revenue.

An increase in explosive density resulted in a decrease in fragmentation size. However, increase in explosive density caused the blasted material to be over-compacted and subject to major hang-ups rather than generating mass flow conditions as hypothesised. As a result, increasing the explosive energy distribution caused lower recovery. Visual observations identified an increase in major hang-ups and slot formations in blast rings corresponding to the increase in explosive density. The slots were formed owing to over-compaction of the blasted ring and cave material resulting in poor flow conditions inside the drawpoint. Walls of compacted cave material, often containing visible smart markers, were visible behind the narrow slots where material had been extracted. Significant dilution occurred during the hang-ups because material from levels above filled the slot formed between the drawpoint and the compacted wall of blasted ore. Power (2004) made similar 
observations during the marker recovery experiments at the Ridgeway SLC. Conversely, reducing the explosive density was found to increase primary recovery, including backbreak, by $8 \%$ on average and cumulative secondary recovery by $10 \%$ compared with baseline measurements. The reduced explosive density did increase the size of some fragmentation metrics. However, no significant increase in oversize tonnage was measured.

Following the detailed cave recovery studies at the Ridgeway SLC, Power (2004) proposed that recovery could potentially be increased by reducing the ring burden. In this research, the reduction in ring burden was hypothesised to be a means to counteract the effects of shallow draw reported at other mines, such as Ridgeway and Perseverance, and increase recovery from the back of the ring. Results of the ring burden trial programs demonstrate that recovery was higher as the burden was increased for the ring burdens tested. The $3 \mathrm{~m}$ ring burden increased recovery by 11 and $8 \%$ on the primary and secondary levels respectively. This behaviour is explained by material flow observations, which are similar to those made in the explosive density trial programs where the decrease in ring burden, and increase in powder factor, corresponded to over-compaction of previously blasted and cave material, resulting in unfavourable gravity flow behaviour. However, the reduction in ring burden did not result in the low recovery and variability measured when the explosive density was increased in Trial Program 4. It is plausible, and theoretically likely, that reducing the ring burden increases the potential for higher recovery from the back of the blasted ring as hypothesised by Power (2004). Though in these experiments, the effects of blast compaction and resulting gravity flow behaviour had a greater influence on recovery for the burdens tested. This effect of over-compaction altered 'normal' material flow behaviour, which negated any increase in recovery owing to the reduction in ring burden.

The ring burden experimental programs determined that a relatively wide range of ring burdens from 2.2 to $3 \mathrm{~m}$ (i.e. $2.6 \mathrm{~m}+/-15 \%$ ) can be successfully blasted using $102 \mathrm{~mm}$ blastholes without significant operational issues. None of these blast rings 'froze' or prevented the brow of the next ring from being accessed due to backbreak. These experiments proved that ring burdens greater than $2.5 \mathrm{~m}$ could be successfully broken using $102 \mathrm{~mm}$ blastholes.

The $P_{50}$ and $P_{80}$ fragmentation metrics were found to have a moderate negative relationship with ring burden. That is, as ring burden is increased, the $\mathrm{P}_{50}$ and $\mathrm{P}_{80}$ metrics decrease. This is the opposite of the expected effect of altering the powder factor, which would normally suggest that a larger amount of explosives per unit of rock would result in more breakage and smaller particle size distributions. This phenomenon can be explained by comparing the results to similar confined blasting experiments conducted in a laboratory environment by Johansson (2011) and underground blast experiments conducted by Wimmer et al. (2013). These experiments found that higher blast confinement resulted in less breakage and larger particle size distributions. Therefore, it can be concluded that under semi-confined blasting conditions in SLC mines, increasing the explosive energy distribution by reducing the ring burden does not necessarily result in smaller fragmentation.

\section{$5 \quad$ Recommendations}

It is recommended that SLC mines monitor the frequency of slot formations in drawpoints as well as ring recovery using cave markers. Should slot formations be common, or (marker) recovery low and irregular, it is possible that over-compaction is occurring. This may be counteracted by reducing the explosive density. The experimental results in this study may not translate to the same changes in recovery at other mines owing to the unique rock mass conditions at each mine. However, these results demonstrate the effects of explosive density on fragmentation and recovery.

This research quantified the impact of ring burden on recovery in an operating SLC mine. It is believed that each individual rock mass condition will have an optimum ring burden in semi-confined SLC conditions. Altering both the ring burden and explosive density was found to affect recovery. For example, a strong brittle rock mass, such as at EHM, may have an optimum burden of approximately $3 \mathrm{~m}$, while a soft rock mass that absorbs energy, such as kimberlite, may correspond to an optimum burden that is smaller. The smaller ring burden in the weaker kimberlite may also require a reduction in explosive density to prevent over-compaction. Additional testing is recommended to further quantify the impact of blast design parameters on recovery in different rock mass conditions. Since recovery has a significant effect on mine 
profitability and shareholder return, it is recommended that SLC mines conduct full-scale experiments to optimise blast design parameters early in the mine life, rather than selecting a benchmarked blast design for the duration of the mine life.

It is recommended that additional cave recovery studies be conducted in different rock mass conditions. Testing of different design parameters should also be undertaken to further improve recovery. Tracking cave flow using networked smart markers to measure the extraction zone and movement growth inside the cave should also be undertaken to improve current understanding of blast movement and gravity flow mechanisms.

Most SLC mines use numerical flow models to optimise the draw strategy and estimate ore reserves and deplete mineral reserves (Campbell 2017). Progress in flow model calibration and marker recovery validation using flow model techniques is provided in Power and Campbell (2016) and Campbell and Power (2017). However, it is not yet possible to integrate the recovery improvements identified in the research into a mine-scale, life-of-mine flow model. It is recommended that additional testing and model calibration be conducted to enable marker recovery data to be used to calibrate such flow models. Such a model could also act as a testbed for testing of blast design parameter and mine layout options prior to mining and to undertaking full-scale testing.

\section{Conclusion}

The purpose of this research was to conduct a series of experiments to quantify the design variables on detonation performance, fragmentation, gravity flow mechanics and recovery. The objective was to determine design parameters that result in higher ore recovery. Specifically designed full-scale experiments were conducted in an operating SLC mine to test the effects of ring burden, explosive density and crosscut heights. The purpose was to measure the effect of design variables on fragmentation and recovery in controlled, production-scale experiments. Prior to this research, the effect of blast design variables, specifically explosive density and ring burden, were not well understood. The experimental results were used to recommend design improvements at EHM and update current design guidelines.

Overall, this research improved current understanding of the impact of design variables on ore recovery in SLC mines. It was identified that recovery in SLC mines is increased by reducing blast energy or powder factor. Increasing the ring burden and decreasing the explosive density were the two design changes that increased primary recovery (including backbreak) and cumulative secondary recovery by 8 to 10\%. A negative correlation between powder factor and recovery was identified for the explosive density and ring burden experimental programs. Most of the literature suggests that altering blast designs to increase the powder factor would result in higher recovery. However, the opposite effect was identified in the research. It was found that over-compaction of the blasted ore had a more significant impact on recovery than the fragmentation size in the experiments conducted. It was also determined that ring burdens greater than $2.5 \mathrm{~m}$ can be successfully broken using $102 \mathrm{~mm}$ blastholes without significantly increasing the amount of oversize material reporting to drawpoints.

\section{References}

ARANZ Geo Limited 2018, Leapfrog Geo, computer software, ARANZ Geo Limited, Christchurch, http://www.leapfrog3d.com/products/leapfrog-geo

Brunton, I 2009, The Impact of Blasting on Sublevel Caving Flow Behaviour and Recovery, PhD thesis, The University of Queensland, Brisbane.

Bull, G \& Page, CH 2000, 'Sublevel caving-today's dependable low-cost 'ore factory", in G Chitombo (ed.) Proceedings of MassMin 2000, The Australasian Institute of Mining and Metallurgy, Melbourne, pp. 537-556.

Campbell, AD 2017, 'A simple and accurate method for ore reserve estimation and mineral resource depletion in caving mines', Proceedings of 13th AusIMM Underground Operators' Conference, The Australasian Institute of Mining and Metallurgy, Melbourne, pp. 253-260.

Campbell, AD 2018, 'Full-scale experiments to measure the effect of crosscut height on recovery in sublevel cave mines', in Y Potvin \& J Jakubec (eds), Proceedings of the Fourth International Symposium on Block and Sublevel Caving, Australian Centre for Geomechanics, Perth, pp. 471-484. 
Campbell, AD \& Power, GR 2017, 'Improving calibration of flow models against SLC marker trials by linking blasting effects to particle mobility', Proceedings of the 13th AusIMM Underground Operators' Conference, The Australasian Institute of Mining and Metallurgy, Melbourne, pp. 11-22.

Campbell, AD \& Thurley, MJ 2017, 'Application of laser scanning to measure fragmentation in underground mines', Transactions of the Institutions of Mining and Metallurgy, Section A: Mining Technology, vol. 126, no. 4, pp 240-247.

Cullum, AJ 1974, The Effects of Confined Blasting on Rock Fragmentation and Flow Characteristics in Sublevel Caving, MEngSc thesis, University of Queensland, Brisbane, p. 161.

DeGagne, DO \& McKinnon, SD 2006, 'The influence of blasting fragmentation on ore', Proceedings of the 41st US Symposium on Rock Mechanics (USRMS): 50 Years of Rock Mechanics - Landmarks and Future Challenges, American Rock Mechanics Association, Alexandria.

Dunstan, G \& Power, G 2011, 'Sub level caving', in P Darling (ed.), SME Mining Engineering Handbook, 3rd edn, Society for Mining, Metallurgy, and Exploration, Englewood.

Elexon Mining 2017, Smart Marker System, apparatus, Elexon Mining, Brendale, viewed 20 May 2017, https://www.elexonmining.com/smart-marker-system-3

Free, GD 1970, Mathematical and Model Studies of the Flow of Material in the Sub-level Caving Mining Method, MEngSc thesis, The University of Queensland, Brisbane.

Gustafsson, P 1998, Waste Rock Content Variations During Gravity Flow in Sublevel Caving: Analysis of Full-scale Experiments and Numerical Simulations, PhD thesis, Luleå University of Technology, Luleå.

Hollins, B \& Tucker, J 2004, 'Draw point analysis using a marker trial at the Perseverance Nickel Mine, Leinster, Western Australia', in A Karzulovic \& M Alfaro (eds), Proceedings of MassMin 2004, Instituto de Ingenieros de Chile, Santiago, pp. $498-502$.

Hustrulid, WA 2000, 'Method selection for large-scale underground mining', in G Chitombo (ed.), Proceedings of MassMin 2000, The Australasian Institute of Mining and Metallurgy, Melbourne, pp. 29-56.

Janelid, I \& Kvapil, R 1966, 'Sublevel caving', International Journal Rock Mechanics and Mining Science, vol. 3, pp. 129-153.

Johansson, D 2011, Effects of Confinement and Initiation Delay on Fragmentation and Waste Rock Compaction, PhD thesis, Luleå University of Technology, Luleå.

Just, GD, Free, GD \& Bishop, GA 1973, 'Optimization of ring burden in sublevel caving', International Journal of Rock Mechanics, Mining Sciences, and Geomechanics, vol. 10, pp. 119-131.

Kosowan, MI 1999, Design and Operational Issues for Increasing Sublevel Cave Intervals at Stobie Mine, MSc thesis, Laurentian University, Sudbury, p. 152.

McCormick, RJ 1968, 'How wide does a draw point draw?', Engineering and Mining Journal, June, pp. 106-116.

Page, CH \& Bull, G 2001, 'Sublevel caving: a fresh look at this bulk mining method', in WA Hustrulid \& RL Bullock (eds), Underground Mining Methods: Engineering Fundamentals and International Case Studies, Society for Mining, Metallurgy, and Exploration, Englewood, pp. 385-394.

Panczakiewicz, T 1977, Optimization of the Sublevel Caving Mining Method Investigated by Physical Models, MSc thesis, University of Melbourne, Melbourne, p 184.

Peters, DC 1984, 'Physical modelling of the draw behaviour of broken rock in caving', Quarterly of the Colorado School of Mines, vol. 79 , no. 1.

Power, GR 2004, Modelling Granular Flow in Caving Mines: Large Scale Physical Modelling and Full scale Experiments, PhD thesis, University of Queensland, Brisbane.

Power, GR \& Campbell, AD 2016, 'Modelling real-time marker data to improve operational recovery in sublevel cave mines', Proceedings of the Seventh International Conference on Mass Mining (MassMin 2016), The Australasian Institute of Mining and Metallurgy, Melbourne, pp. 105-110.

Quinteiro, CR, Larsson, L \& Hustrulid, WA 2001, 'Theory and practise of very large scale sublevel caving', in WA Hustrulid \& RL Bullock (eds), Underground Mining Methods: Engineering Fundamentals and International Case Studies, Society for Mining, Metallurgy, and Exploration, Englewood, pp. 381-384.

Rustan, A 2000, 'Gravity flow of broken rock - what is known and unknown', in G Chitombo (ed.) Proceedings of MassMin 2000, The Australasian Institute of Mining and Metallurgy, Melbourne, pp. 557-567.

Stazhevskii, SB 1996, 'Features of flow of broken rock in extraction of ores with sublevel caving', Journal of Mining Science, vol. 32, no. 5, pp. 403-416.

Wimmer, M 2010, Gravity Flow of Broken Rock in Sublevel Caving (SLC) - State-of-the-Art, Swebrec Report 2010:P1, Luleå University of Technology, Luleå.

Wimmer, M, Nordvist, A, Ouchterlony, F, Nyberg, U \& Furtney, J 2013, 'Burden movement in confined drift wall blasting tests studied at the LKAB Kiruna SLC mine', in S Sinha (ed.), Proceedings 10th International Symposium on Rock Fragmentation by Blasting, Taylor \& Francis Group, London, pp. 373-383. 
